DATE

NILONEMA GYMNARCHI Khalil, $1960 \ldots \ldots+\ldots \quad \ldots \quad 55$

OXYSOMATIUM SRINAGARENSIS Fotedar, $1960 \quad \ldots \quad 141$

OXYSPIRURA ALAUDA Ali, $1960 \quad \ldots . \quad \ldots \quad \ldots . \quad \ldots 24$

OXYSPIRURA ASIATICA Ali, $1960 \quad \ldots \quad \ldots \quad \ldots \quad \ldots \quad 228$

OXYSPIRURA $B U C K L E Y I$ Ali, $1960 \quad \ldots \quad \ldots \quad \ldots \quad \ldots \quad 232$

OXYSPIRURA CHRYSOMMA Ali, $1960 \quad \ldots \quad \ldots \quad 230$

OXYSPIRURA LALAGEA Ali, $1960 \quad \ldots \quad \ldots \quad \ldots \quad \ldots \quad 234$

OXYSPIRURA LEROUXI Ali, $1960 \quad \ldots \quad \ldots \quad \ldots \quad \ldots \quad 238$

OXYSPIRURA LOBIPLUVIA Ali, $1960 \ldots . \quad \ldots . \quad \ldots \quad 226$

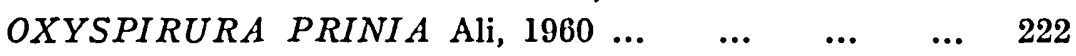

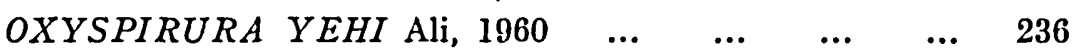

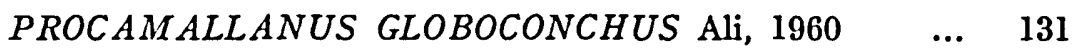

PROCAMALLANUS OPHICEPHALUS Ali, $1960 \quad \ldots \quad 132$

PROTEOCEPHALUS SANDONI Lynsdale, $1960 \quad \ldots \quad 43$

SPLENDIDOFILARIA KASHMIRENSIS Amir and Ali,

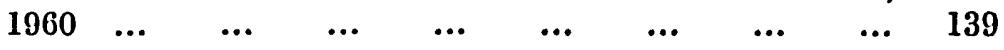

\title{
CORRIGENDUM iN Volume XXXIV
}

Page 90, lines 4-5 (Table 2) for Cercaria Petersen $I$ read Cercaria I, Petersen.

Actual Dates of Publication for Volume XXXIII

$\begin{array}{llll}\text { No. } 1 & \ldots & \ldots & \text { 10th June } 1959 \\ \text { Nos. } 2 / 3 & \ldots & \ldots & \text { 19th October 1959 } \\ \text { No. } 4 & \ldots & \ldots & \text { 31st December 1959 }\end{array}$

